\title{
Fostering Teacher-Student Interaction and Learner Autonomy by the I-TUTOR Maps
}

\author{
Vincenzo Cannella ${ }^{1}$, Laura Fedeli ${ }^{2}$, Arianna Pipitone ${ }^{1}$, Roberto Pirrone ${ }^{1}$, and \\ Pier Giuseppe Rossi ${ }^{2}$ \\ 1 Dep.t of Chemical, Management, Computer, Mechanical Eng., Univ. of Palermo \\ Viale delle Scienze, Bdg 6, 90128 Palermo (Italy) \\ 2 Department of Education, Cultural Heritage and Tourism, University of Macerata \\ P.le Bertelli, 62100, Macerata (Italy) \\ \{vincenzo.cannella26, arianna.pipitone, roberto.pirrone\}@unipa.it \\ \{pg.rossi, laura.fedeli\}@unimc.it
}

\begin{abstract}
The paper analyses the use of an automatically generated map as a mediator; that map visually represents the study domain of a university course and fosters the co-activity between teachers and students. In our approach the role of the teacher is meant as a mediator between the student and knowledge. The mediation (and not the transmission) highlights a process in which theres no deterministic relation between teaching and learning. Learning is affected by the students previous experiences, their own modalities of acquisition and by the inputs coming from the environment. The learning path develops when the teachers and the students visions approach and, partly, overlap. In this case we have co-activity. The teacher uses artifacts-mediators in such a process (Bruner). The automatically generated map can be considered a mediator. The paper describes the experimentation of the artifact to check if its use fosters: (1) the elicitation of the different subjects perspectives (different students and the teachers), and (2) the structural coupling that is the creation of an empathic process between the perspectives of the teacher and the student as the way to enable co-activity processes between teaching and learning.
\end{abstract}

Keywords: Co-actvity, Structural Coupling, Mediation, Latent Semantic Analysis, Self Organizing Map, Zoomable User Interfaces

\section{Introduction}

The artifact described in the paper was created within the project I-TUTOR (Intelligent Tutoring for Lifelong Learning - http://www. intelligent-tutor . $\mathrm{eu} /$ ) approved by the European Community. The research group composed by researchers of the information science field and education field has been working for the last years in the development of AI enabled artifacts for e-learning [1][2][3]. The system aims at helping teachers and students foster a professional and enactive approach. In such a direction some plug-ins for the Moodle Learning Management System have been developed. The I-MAP plug-in is a concept map, 
that represents the course domain in terms of all its relevant topics as they're described by the teacher. It relies on the creation of two semantic spaces aimed at modeling both the course topics and the students interaction with the VLE: the conceptual space and the activity space (one for each student). Latent Semantic Analysis (LSA) has been adopted to compute the semantic space generated from a document corpus on the basis of the occurrence frequencies of a set of meaningful terms in each document. A self-Organizing Map (SOM) neural network is used for both learning the topology of data in the space itself and clustering input vectors. Finally, the map represents the 2D projection of the SOM lattice after the training as a grid of cells. The map has been developed as a Zooming User Interface representing graphically documents and topics. The reader is referred to [4] for a detailed description. In the experimentation the map was used to activate a co-activity/empathy [5]. Co-activity and empathy are meant as a progressive approach between the teachers perspective and the students one. At the beginning the savy knowledge (of the teacher) and knowledge that comes from the common sense (of the student) can show many elements of discontinuity. Thanks to the didactical transposition [6] and to the listening the teaching and learning process lets the actors reach, through continuous adaptations, a level of consistency between the two perspectives. The result of such a process is the structural coupling [7][8][9] In such a direction its necessary that the teacher can have multiple and flexible mediators, that is, artifacts and processes (active, iconic, analogic and simboli; [10]) that let the teacher represent reality. The path is organized in teaching and learning activities [11] that let the student experience in an active way the learning paths (open-ended activities). The use of the map is set in this direction: from the teachers viewpoint the maps nodes are the key words of the course and, then, the map represents the savy knowledge related to the course domain; since the maps nodes are not connected the student can freely build a net among the concepts selecting both the starting node and the path to be created.

\section{Experimentation and Findings}

The objective of the experimentation is aimed at verifying (1) if the teaching process activates an empathic attitude (co-activity) between the teacher and the student e (2) if the map can let students create a personalized path. The overall research design is framed within a qualitative approach implying a phenomenological method of inquiry. The experimentation involved a small sample of participants: one group of 10 students enrolled in the face-to-face graduate course in General Didactics, a second group composed by 5 students studying in e-learning modality in the same graduate course and a third group of 10 students who followed the course in the past years with a different syllabus.. The participants of each group were interviewed by the teacher through a semi-structured open conversation [12]. Students were asked to examine the map generated by I-MAP (that has just nodes and no hedges) and to interpret it describing in a narrative way the path that could connect all or a part of the map nodes ac- 
cording to their own logic. The task implied also to make it explicit the meaning of the connection among the nodes and to discuss it with the teacher. Gathered data were: the net built by each student and the linguistic analysis of the description made by students themselves and focused also on the presence of the deixis phenomenon. The use of the I-MAP tool demonstrated (Table 1) its efficacy in group 1 and 2 both in the impact in the processes of co-activity teacher-students, since even if the maps created are different and with personalized elements, they showed to be consistent with the global approach of the course. Also the linguistic aspects highlight the students attitude towards the map according to a co-activity logic. Besides the use of the pronoun we" and the informal register preferred by students show the presence of a dialogic process between the teacher and the student. Groups 1 and 2 had a similar behavior compared to group 3 where a wider dispersion emerges in the occurrences of the node used. The map lets every student express his/her own perspective. As highlighted in Table 1 students created different paths starting from different nodes. There were two main options: some students (starting from the node action) developed a path more focussed on key concepts, others (starting from the node design) reported the teachers habitus from the design step to the assessment.

\begin{tabular}{|l|c|c|c||c|c|c|}
\hline \multirow{2}{*}{ Node name } & \multicolumn{3}{|c||}{ Visited } & \multicolumn{3}{c|}{ Start } \\
\cline { 2 - 7 } & Group 1 & Group 2 & Group 3 & Group 1 & Group 2 & Group 3 \\
\hline Apprendimento & $12 \%$ & $7 \%$ & $13 \%$ & $13 \%$ & $0 \%$ & $17 \%$ \\
Azione & $18 \%$ & $19 \%$ & $9 \%$ & $38 \%$ & $55 \%$ & $0 \%$ \\
Contesto & $14 \%$ & $8 \%$ & $14 \%$ & $13 \%$ & $0 \%$ & $17 \%$ \\
Costruttivismo & $4 \%$ & $5 \%$ & $8 \%$ & $0 \%$ & $0 \%$ & $17 \%$ \\
Dispositivo & $14 \%$ & $14 \%$ & $7 \%$ & $0 \%$ & $0 \%$ & $0 \%$ \\
Formazione & $6 \%$ & $8 \%$ & $13 \%$ & $0 \%$ & $0 \%$ & $0 \%$ \\
Progettazione & $12 \%$ & $13 \%$ & $9 \%$ & $38 \%$ & $0 \%$ & $33 \%$ \\
Progetto & $6 \%$ & $7 \%$ & $10 \%$ & $0 \%$ & $45 \%$ & $17 \%$ \\
Valutazione & $12 \%$ & $14 \%$ & $14 \%$ & $0 \%$ & $0 \%$ & $0 \%$ \\
\hline std. dev. & 0.05 & 0.05 & 0.03 & 0.16 & 0.22 & 0.12 \\
\hline
\end{tabular}

Table 1. Results of the experimentation

In the future we plan to let the user have the chance to choose the starting node not only in the interpretation of the map, but also in its construction, enhancing the awareness of the importance of this choice and its effects.

\section{References}

1. Rossi, P.G., Carletti, S., Bonura, D.: A platform-independent tracking and monitoring toolkit. In: Proc. of the AAAI 2009 Fall Symposium in Cognitive and Metacognitive Educational Systems (FS-09-02), Arlington VA, USA, AAAI Press (Nov. 5-7 2009) 76-80 
2. Pirrone, R., Azevedo, R., Biswas, G.: Why metacognition in modern educational systems? In: AAAI Fall Symposium - Technical Report. Volume FS-09-02. (2009) vii-viii

3. Bentivoglio, C.A., Bonura, D., Cannella, V., Carletti, S., Pipitone, A., Pirrone, R., Rossi, P.G., Russo, G.: Intelligent agents supporting user interactions within self regulated learning processes. Journal of e-Learning and Knowledge Society-English Version 6(2) (2010) 27-36

4. Pipitone, A., Cannella, V., Pirrone, R.: Automatic concept maps generation in support of educational processes. Journal of e-Learning and Knowledge Society 10(1) (2014) 85-103

5. Berthoz, A., Jorland, G., eds.: L'Empathie. Odile Jacob, Paris, France (2004)

6. Chevallard, Y.: La transposition didactique: du savoir savant au savoir enseigné. La Pensée Sauvage, Grenoble, France (1991)

7. Maturana, H., Varela, F.: Autopoiesis: the organisation of the living. In Maturana, H., Varela, F., eds.: Autopoiesis and cognition; the realization of the living. Reidel, Boston, MA, USA (1980)

8. Proulx, J. Simmt, E.: Enactivism in mathematics education: moving toward a re-conceptualization of learning and knowledge. Enactivism in mathematics education: moving toward a re-conceptualization of learning and knowledge 4(1) (2013) 59-79

9. Rossi, P.e.a.: Enactivism and didactics. some research lines. Education Science and Society 4(1) (2013) 37-57

10. Bruner, J.: Toward a theory of instruction. Belkapp Press, Cambridge, MA, USA (1966)

11. Laurillard, D.: Teaching as a design science. Building pedagogical patterns for learning and teaching, New York (2012)

12. Corbetta, P.: La ricerca sociale: metodologia e tecniche. III Le tecniche qualitative. Il Mulino, Bologna, Italy (2003) 